\title{
Kelayakan Usaha Ikan Bandeng Di Kecamatan Seruyan Hilir Kabupaten Seruyan
}

\section{Feasibility Analysis Of Milkfish Business In Seruyan District Hilir Seruyan District}

\author{
Lili Winarti' Rokhman Permadi \\ Universitas Darwan Ali \\ liliwinarti14@gmail.co.id
}

\begin{abstract}
ABSTRAK
Besarnya produksi bandeng yang dihasilkan pada tambak ikan bandeng di Kecamatan Seruyan Hilir akan menyebabkan terjadinya persaingan harga, dimana ketika hasil produksi yang berbarengan menyebabkan harga akan ditententukan oleh tengkulak, sehingga petani tidak dalam posisi menentukan harga selain harga yang ditentukan oleh tengkulak, adapun penelitian ini bertujuan untuk menganalisis kelayakan finansial usaha tambak ikan bandeng di Kecamatan Seruyan Hilir Kabupaten Seruyan. Metode yang digunakan adalah yaitu metode sensus, metode sensus merupakan metode penelitian yang menggunakan semua individu yang ada dalam populasi, adapun responden dalam penelitian ini berjumlah 29 orang petani ikan bandeng. Analisis data yang digunakan adalah analisis kuantitatif untuk menganalisis biaya-biaya yang dikeluarkan selama kegiatan mulai dari biaya investasi, operasional produksi dan Analisis finansial digunakan untuk mengetahui kelayakan usaha tambak ikan bandeng dengan menggunakan kriteria-kriteria kelayakan investasi yaitu: Net Present Value(NPV), Internal rate of Return (IRR), Net Benefit Cost Rasio (Net B/C), Payback Period . Adapun hasil penelitian ini adalah bahwa usaha tambak ikan bandeng berdasarkan 4 criteria investasi yang digunakan di kecamatan seruyan hilir layak untuk usahakan, hal ini bisa dilihat dari nilai NPV positif yaitu sebesar Rp 114.513.540,11, nilai IRR yang lebih besar dari tingkat suku bunga yaitu sebesar $160 \%$, nilai net B/C sebesar 6,56 dan pay back period usaha tambak ikan bandeng ini 7 bulan.
\end{abstract}

Kata kunci : Kelayakan; Finansial; usaha, ikan bandeng

\section{ABSTRACT}

The large amount of milkfish production produced in milkfish ponds in Seruyan Hilir District will cause price competition, where when the concurrent production results cause prices to be determined by middlemen, so farmers are not in a position to determine prices other than prices determined by middlemen, while this study aims to analyze the financial feasibility of milkfish ponds in Seruyan Hilir district, Seruyan Regency. The method used is the census method, the census method is a research method that uses all individuals in the population so that, as for the respondents in this study were 29 milkfish farmers. Analysis of the data used is a qualitative analysis to analyze the costs incurred during activities ranging from investment costs, production operations and financial analysis is used to determine whether or not feasible milkfish pond business using investment feasibility criteria, namely: Net Present Value (NPV), Internal rate of Return (IRR), Net Benefit Cost Ratio (Net B / C), Payback Period. The results of this study are that the milkfish pond business based on 4 investment criteria used in the Seruyan Downstream sub-district is feasible to try, this can be seen from the positive NPV value of IDR 114,513,540.11, IRR value greater than the interest rate namely by 160\%, the net $B$ / $C$ value is 6.56 and the pay back period for this milkfish pond business is 7 months.

Key word: Feasibility; Financial; Business; Milkfish.

\section{PENDAHULUAN}

Kabupaten Seruyan memiliki potensi yang cukup besar di bidang perikanan, baik perikanan tangkap maupun usaha budidaya perikanan, dan usaha budidaya perikanan memiliki prospek ekonomi yang sangat menjanjikan untuk memenuhi kebutuhan akan ikan, baik yang berupa segar maupun olahan, masih belum mencukupi kebutuhan konsumen. Budidaya perikanan darat dapat dilakukan dengan memanfaatkan wilayah sepanjang pesisir pantai yang merupakan nilai lebih perairan Indonesia dan biasanya dikenal dengan nama tambak dan di Kabupaten Seruyan salah satu jenis ikan yang memiliki potensi dan banyak di budidayakan di tambak yang di buat di sepanjang wilayah tepi pantai adalah ikan bandeng.

Ikan bandeng merupakan salah satu jenis ikan budidaya air payau (tambak) yang sekaligus juga merupakan bahan konsumsi masyarakat luas, sehingga mempunyai prospek yang cukup cerah untuk dikembangkan di wilayah pesisir Kabupaten Seruyan, selain itu ikan bandeng mempunyai toleransi salinitas yang tinggi sehingga dapat dibudidayakan ditambak yang berair payau. Di kabupaten seruyan jumlah 
produksi ikan bandeng adalah yang terbesar yaitu sekitar 2.272,80 ton per tahun di bandingkan jumlah produksi perikanan budidaya tambak lainnya, dan jumlah produksi selalu meningkat sepanjang tahun (Dislutkan, 2019).

Pentingnya pengetahuan bagi petani tambak bandeng terhadap factor produksi dalam budidaya ikan bandeng berpengaruh terhadap hasil produksi ketika panen, dan keberhasilan suatu usaha budidaya ikan dapat ditunjang dengan ketersedian factor produksi secara kontinyu dalam jumlah yang tepat, menurut Soekartawi (1991) kuantitas factor produksi sangat menentukan besar kecilnya produksi yang di peroleh. Selain itu dampak lain dari banyaknya produksi bandeng yang dihasilkan akan menyebabkan terjadinya persaingan harga pada tingkat tengkulak, dimana ketika hasil produksi yang berbarengan menyebabkan harga akan ditententukan oleh tengkulak, sehingga petani tidak dalam posisi menentukan harga selain harga yang ditentukan oleh tengkulak. Berdasarkan uraian latar belakang tersebut, maka penelitian ini bertujuan untuk mengalisis kelayakan finansial usaha tambak bandeng di Kabupaten Seruyan.

\section{METODELOGI PENELITIAN}

Penelitian ini dilaksanakan di Kabupaten Seruyan di wilayah pesisir yaitu Desa Sungai Undang Kecamatan Seruyan Hilir yang banyak terdapat tambak bandeng, responden di dalam penelitian ini adalah petani tambak bandeng yang aktif berjumlah 29 orang responden. Adapun penelitian ini dilaksanakan pada bulan April 2020 sampai Juni 2020 di Kuala Pembuang Kecamatan seruyan Hilir Kabupaten seruyan.

Data yang digunakan dalam penelitian ini dikumpulkan dengan cara melakukan wawancara dan memberikan daftar pertanyaan (kuisioner) secara langsung kepada responden, sedangkan data-data penunjang lainnya diperoleh dengan melakukan studi pustaka pada instansi terkait seperti Laporan Tahunan Dinas Kelautan dan Perikanan Kabupaten Seruyan tahun 2019, Seruyan Dalam Angka Badan Pusat Statistik tahun 2019, suku bunga KUR dari BRI tahun 2019 dan beberapa publikasi lainnya yang dianggap relevan.

Analisis kelayakan aspek finansial dalam usaha tambak ikan bandeng ini menggunakan beberapa kriteria, yaitu: Analisis nilai bersih sekarang (Net Present Value/NPV), tingkat pengembalian investasi (Internal Rate of Return/IRR), masa pengembalian investasi (Payback Period), Net benefit and Cost Ratio (Net B/C Ratio) atau angka perbandingan antara present value dari net benefit yang positif dengan present value dari net benefit yang negatif (Ibrahim, 2009).

Beberapa asumsi dasar yang digunakan dalam penelitian analisis kelayakan usaha tambak ikan bandeng di Kecamatan seruyan Hilir Kabupaten Seruyan yaitu 1) pendapatan adalah total penerimaan yang diperoleh pengusaha setelah dikurangi total biaya dalam satuan Rp/ton per tahun, 2) Penerimaan adalah jumlah produksi dikali dengan harga yang dihitung dalam satuan $\mathrm{Rp} / \mathrm{kg}$ per tahun, 3) Tahun dasar yang digunakan dalam penelitian ini adalah tahun $2019,4)$ Modal yang digunakan diasumsikan modal sendiri, 5) Umur proyek dari analisis kelayakan usaha tambak ikan bandeng adalah 3 tahun, 6) produksi yang dihasilkan 2 kali dalam setahun, 7) harga jual Rp 15.000/kg, 8).Umur ekonomis adalah depresiasi atau penyusutan dalam akuntansi adalah penyebaran biaya asal suatu aktiva tetap (bangunan, alat dll) selama umur perkiraannya. 9). Tingkat suku bunga(discount rate) adalah persentase dari pokok utang yang dibayarkan sebagai imbal jasa ( bunga ) dalam suatu periode tertentu, berdasarkan suku bunga Kredit Usaha Rakyat (KUR) Bank BRI tahun 2019.

\section{Hasil dan Pembahasan \\ Karakteristik Responden Berdasarkan Tingkat Pendidikan}

Pendidikan formal petani adalah jenjang pendidikan yang ditempuh oleh petani, dihitung dari sistem pendidikan sekolah yang telah berhasil ditamatkan oleh petani. Tingkat pendidikan seseorang akan mempengaruhi kebijakan dalam mengambil suatu keputusan pada kegiatan usahatani. Semakin pesatnya perkembangan teknologi dewasa ini membutuhkan seseorang dengan tingkat pendidikan semakin tinggi agar dapat mengikuti perkembangan teknologi tersebut dengan baik, sehingga akan berdampak positif pada produktivitas, pendapatan dan pada akhirnya akan meningkatkan kesejahteraan. 


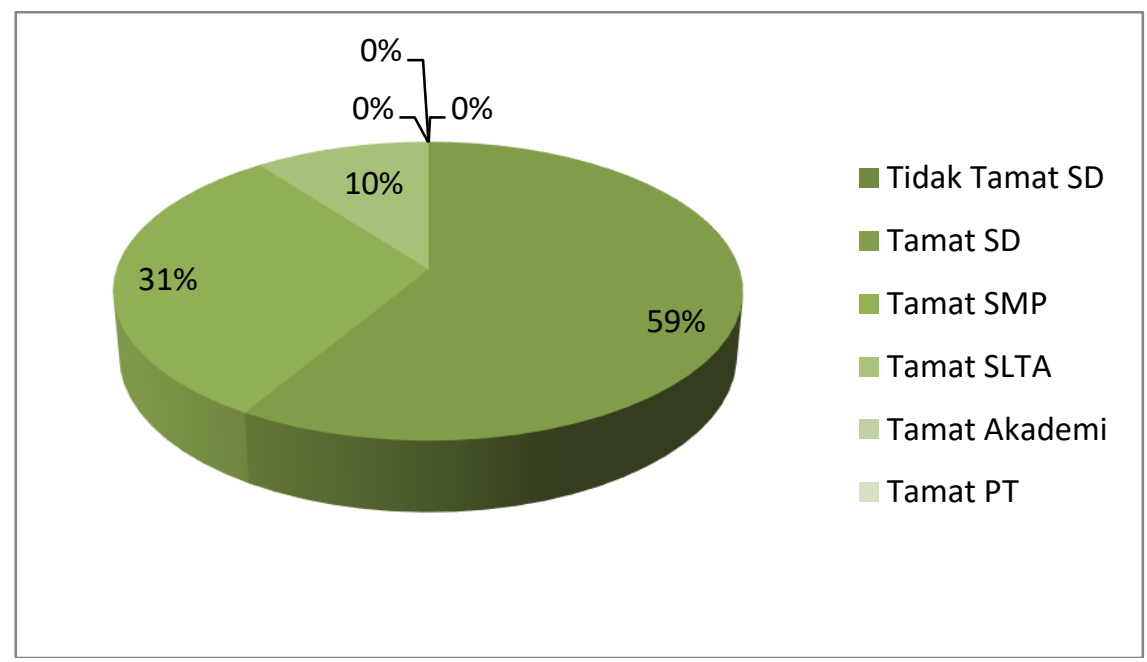

Gambar 1. Pendidikan responden

Mayoritas tingkat pendidikan petani tambak bandeng di Kecamatan Seruyan Hilir Kabupaten Seruyan adalah tamat sekolah dasar (SD) sebesar 59\%, rendahnya tingkat pendidikan menurut Tadaro (1998) menyebabkan mereka tidak mendapatkan pekerjaan pada sector-sektor produktif lainnnya, dan usaha tambak bandeng mereka pilih karena tidak memerlukan pendidikan yang tinggi dan keahlian khusus dalam pengelolaan usaha budidaya tambak bandeng di kecamatan seruyan hilir kabupaten seruyan, karena lebih banyak menitik beratkan pada kemampuan dan pengalaman secara turuntemurun dari orang tua atau keluarga petani tambak bandeng tersebut, hal ini sejalan menurut penelitian Winarti, L, Herlina S, Permadi R (2018) bahwa usaha yang tidak memerlukan tingkat pendidikan tingggi biasa merupakan usaha warisan atau mengandalkan kemampuan dalam mengelola usahanya, hal mengindikasikan bahwa pelaku usaha memiliki pengalaman yang cukup banyak dalam menjalankan usahanya. Selain itu rendahnya tingkat pendidikan, menyebabkan petani tambak ikan bandeng tidak mau mengembangkan dan menerima usulan dan saran untuk pengembangan usahanya ke arah semi intensif dengan alasan tradisional lebih menguntungkan, dan lebih mudah dalam pengelolaan.

\section{Karakteristik Responden Berdasarkan Umur Umur akan mempengaruhi} keberhasilan seorang petani dalam mengelola usaha tambaknya, dalam penelitian ini mayoritas umur petani tambak berkisar antara 36-46 tahun dengan persentase sebesar 38\%, dimana usia tersebut adalah usia produktif dalam menjalan kan usahanya, hal ini sejalan dengan penelitian Faiq $\mathrm{H}$, Hastuti D, Sasongko L.A (2012) bahwa Petani yang berusia produktif memiliki sifat ketahanan fisik yang lebih besar dibandingkan petani yang berusia non produktif

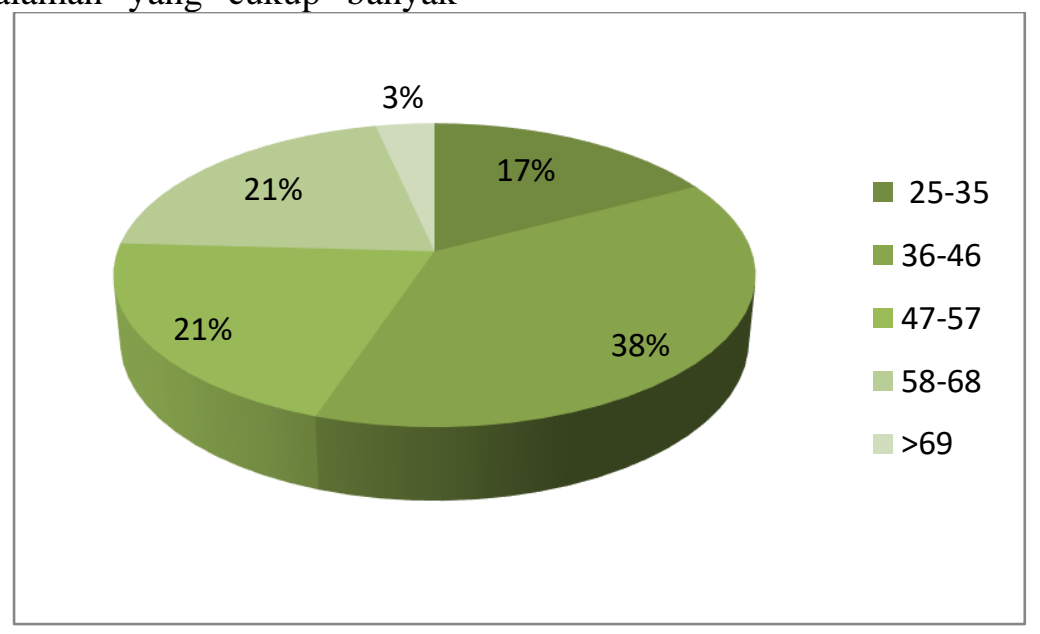

Gambar 2. Umur Responden 


\section{Karakteristik Responden Lama berusaha}

Lamanya berusaha akan akan mempengaruhi kemampuan dan kebiasaan petani tambak bandeng dalam mengelola usaha tambak bandengnya, hal ini akan mempengaruhi tingkat produksi yang dihasilkan dari usaha yang dilakukannnya, dari hasil yang di peroleh petani ikan bandeng di kecamatan seruyan hilir memiliki lama usaha yang cukup lama yaitu sekitar 15 tahun, hal ini menunjukkan bahwa petani tambak bandeng di wilayah tersebut memiliki pengalaman yang cukup baik dalam mengelola usaha yang dilakukannnya. Pada penelitian ini $45 \%$ petani tambak bandeng telah melakukan usahanya selama 13 tahun dan $34 \%$ selama 15 tahun, hal ini membuat petani tambak bandeng yang ada di kecamatan seruyan hilir memiliki cukup pengalaman dalam menjalankan usaha.

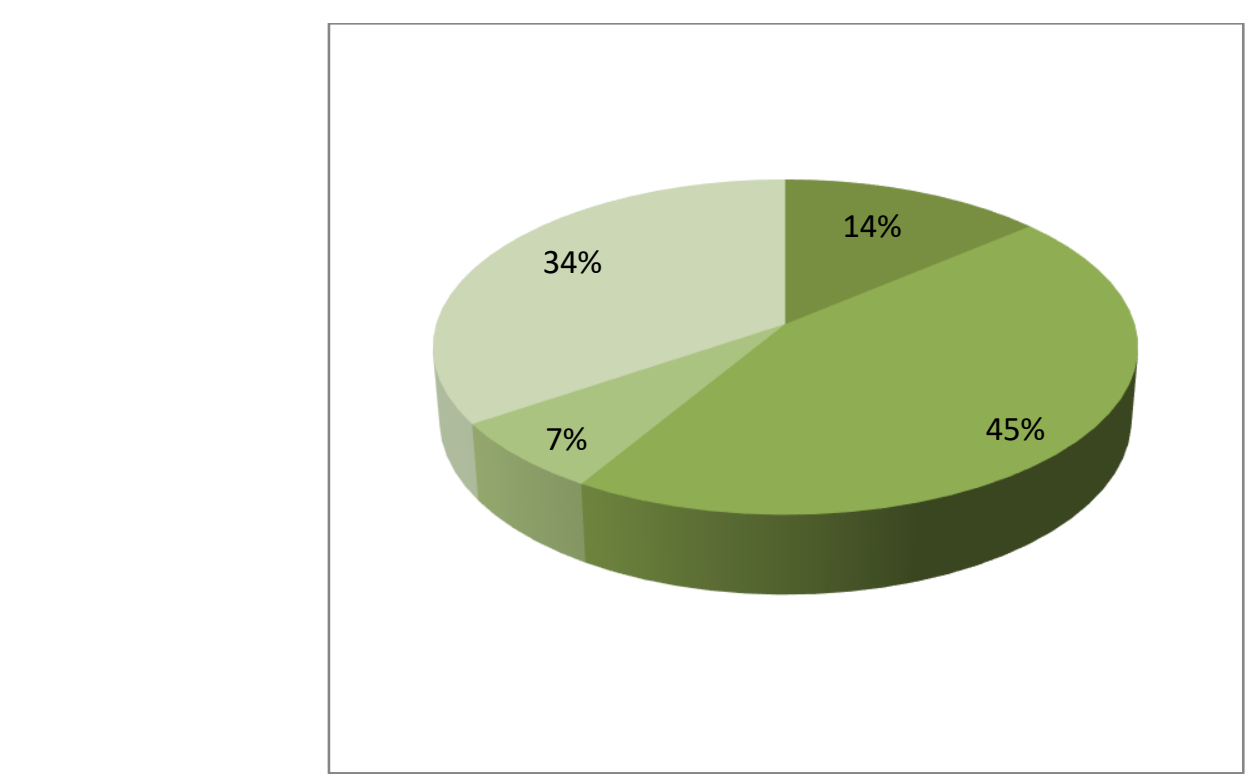

\section{Karakteristik Responden Berdasarkan} Jumlah Anggota Keluarga Jumlah anggota

keluarga mempengaruhi motivasi seorang petani dalam mengelola usaha tambak bandengnya, selain itu ketersedian anggota keluarga merupakan penyedia tenaga kerja yang murah dan siap pakai yang bisa digunakan membantu kegiatan usaha tambak bandeng dan mayoritas jumlah anggota keluaraga petani tambak bandeng berjumlah 4 orang jumlah anggota keluarga. Dan untuk usaha tambak bandeng yang ada di kecamatan seruyan hilir masih bersifat tradisional, mereka hanya memakai tenaga kerja dalam keluarganya saja, sehingga seluruh anggota keluarga ikut terlibat dalam kegiatan tambak bandeng yang mereka lakukan.

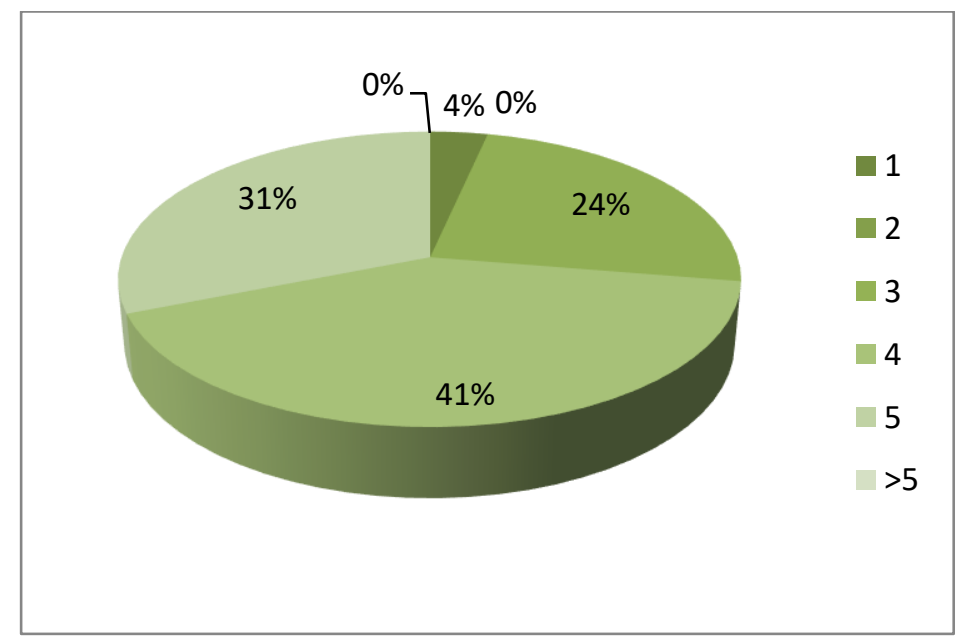

Gambar 4. Jumlah anggota keluarga responden 
Analisis Kelayakan Finansial usaha

Analisis kelayakan financial usaha tambak ikan bandeng, menunjukkan bahwa nilai NPV adalah positif atau lebih dari satu yang berarti usaha yang dilakukan menurut nilai sekarang adalah menguntungkan untuk dilaksanakan, dan berdasarkan hasil perhitungan analisis kelayakan financial usaha tambak ikan bandeng diperoleh nilai untuk kriteria kelayakan usaha seperti pada Tabel 1.1 berikut:

Tabel 1. Kriteria Kelayakan Finansial Usaha Tambak Ikan Bandeng di Kecamatan Seruyan Hilir Kabupaten Seruyan.

\begin{tabular}{cll}
\hline No. & \multicolumn{1}{c}{ Kriteria Kelayakan } & \multicolumn{1}{c}{ Nilai } \\
\hline 1 & Net Present Value (NPV) (Rp) & Rp 114.513.540,11 \\
2 & Internal Rate of Return $(\%)$ & $160 \%$ \\
3 & Net Benefit Cost Ratio (Net B/C) & 6,56 \\
4 & Payback Period (Tahun) & 7 bulan \\
\hline
\end{tabular}

Sumber: Pengolahan Data Primer Tahun 2020.

Nilai IRR yang digunakan untuk menghitung tingkat suku bunga yang menyamakan nilai sekarang investasi dengan nilai sekarang, dan menurut Gittinger (1986) suatu investasi dianggap layak apabila memiliki IRR lebih besar dari tingkat suku bunga yang berlaku dan suatu investasi dianggap tidak layak apabila memiliki nilai IRR yang lebih kecil dari tingkat suku bunga yang berlaku, dari hasil perhitungan didapat IRR sebesar $160 \%$, dimana nilai ini lebih besar dari tingkat suku bunga yang digunakan sebesar 7\%.

Net B/C ini menunjukkan gambaran berapa kali lipat manfaat (benefit) yang diperoleh dari biaya (cost) yang dikeluarkan, berdasarkan hasil penelitian di peroleh nilai Net B/C sebesar 6,56, dimana nilai $\mathrm{Net} B / C$ lebih dari satu yang berarti setiap satu rupiah yang dikeluarkan akan mendapat atau menghasilkan manfaat bersih melebihi tambahan biaya yang dikeluarkan dan hal ini mengindikasikan usaha tambak ikan bandeng ini layak untuk dilakukan dilihat dari benefit yang di keluarkan lebih besar dari dari manfaatnya yang diberikan.

Nilai Payback period merupakan jangka waktu tertentu yang menunjukkan terjadinya arus penerimaan (cash in flows) secara kumulatif sama dengan jumlah investasi dalam bentuk present value, dan nilai payback period yang diperoleh sebesar 7 bulan atau kurang lebih selama satu periode usaha tambak yang dilakukan, nilai ini berarti usaha tambak ikan bandeng layak dilakukan dilihat dari analisis financial usahanya. Selain itu, menurut hasil penelitian Winarti, L (2017) bahwa usaha ikan bandeng di Kecamatan Seruyan Hilir masih menguntungkan petani dan layak diusahakan dilihat dari analisis resiko usahanya yang dilakukan dengan menilai harga, produksi dan pendapatan yang di hasilkan dari usaha tambak ikan bandeng di Kecamatan Seruyan Hilir.

Berusaha tambak ikan bandeng yang dilakukan oleh petani di Kecamatan Seruyan Hilir memiliki prosfek yang menjanjikan untuk di kembangkan, disatu sisi usaha tambak bandeng yang dilakukan tidak terlalu banyak mengeluarkan biaya, hal ini disebabkan tambak bandeng yang ada di kecamatan seruyan hilir masih di usahakan secara tradisional dan tidak ada biaya untuk pakan yang di keluarkan, karena berdasarkan wawancara dengan petani tambak bandeng, bahwa ikan bandeng yang mereka budidayakan hanya makan lumut, ganggang dan klekap yang tumbuh dari kolam mereka, sehingga waktu yang mereka butuhkan untuk panen menjadi lebih lama, dan jika petani mau memberikan pakan tambahan untuk ikan bandeng mereka maka umur panen bisa lebih cepat, hal ini sejalan dengan penelitian Ula, M \& Kusnadi, N (2017) bahwa tujuan dari penggunaan pakan ini untuk mempercepat pertumbuhan bandeng, sehingga waktu yang dibutuhkan budidaya lebih pendek dibanding budidaya tradisional, meskipun mampu mempercepat pertumbuhan bandeng, tidak semua petani bandeng beralih ke budidaya semiintensif, karena budidaya semi intensif memerlukan biaya yang lebih besar terutama pada penggunaan pakan dan biaya tenaga kerja, karena itu petani tambak ikan bandeng lebih memilih yang tradisional. Selain itu menurut Triyanti, R \& Hikmah (2015) bahwa 
faktor pendukung yaitu aspek teknis (lingkungan), besarnya permintaan produk, adanya saluran pemasaran yang lancar, kemitraan antara pedagang dengan pembudidaya, dan aspek keuangan mempengaruhi keberhasilan budidaya ikan bandeng, selain itu di Kecamatan Seruyan Hilir memiliki kendala lain di dalam proses pemasarannya yaitu akses jalan menuju lokasi tambak di kecamatan seruyan hilir masih sulit untuk dilalui, hal ini menjadi kendala ketika musim panen tiba, karena akan ada biaya tambahan yang dikeluarkan oleh petani tambak bandeng untuk mengangkut ikan bandeng hasil panen mereka, ke lokasi yang mudah di akses oleh tengkulak ikan bandeng.

\section{KESIMPULAN}

Berdasarkan tujuan dan hasil pembahasan pada penelitian ini, maka dapat disimpulkan bahwa usaha tambak ikan bandeng berdasarkan 4 criteria investasi yang digunakan di kecamatan seruyan hilir layak untuk usahakan, hal ini bisa dilihat dari nilai NPV positif yaitu sebesar Rp 114.513.540,11, nilai IRR yang lebih besar dari tingkat suku bunga yaitu sebesar $160 \%$, nilai net $\mathrm{B} / \mathrm{C}$ sebesar 6,56 dan pay back period usaha tambak ikan bandeng ini 7 bulan.

\section{DAFTAR PUSTAKA}

BPS. 2019. Seruyan Dalam Angka. Kabupaten Seruyan.

Laporan Tahunan Dinas Kelautan dan Perikanan. 2019. Kabupaten Seruyan.

Faiq H, Hastuti D, Sasongko L.A 2012. Analisis Pendapatan Budidaya Bandeng Kelurahan Tugurejo Kecamatan Tugu Kota Semarang. VOL 8. NO. 1, 2012: HAL $72-85$.

https://publikasiilmiah.unwahas.ac.id/i ndex.php/Mediagro/article/view/1309

Ibrahim, Y. 2009. Studi Kelayakan Bisnis. Edisi Revisi. Penerbit Rineka Cipta. Jakarta.
Gittinger, 1986. Analisis Ekonomi ProyekProyek Pertanian. UI-Press Johns Hopkins Seri Edi dalam Pembangunan Ekonomi Indonesia .

Soekartawi, 1991. Agribisnis Teori dan Aplikasinya. PT. Raja Grafindo Persada. Jakarta.

Tadaro, M.P. 1998. Pembangaunan Ekonomi di duania Ke Tiga. Edisi Ke Enam. Penerbit Erlangga. Jakarta.

Triyanti, R dan Hikmah , 2015. Analsis Kelayakan Usaha Budidaya Udang dan Bandeng: Studi Kasus Kecamatan Pasekan Indramayu. vol. 1, no. 1, tahun $2015 \quad \mathrm{http}: / /$ ejournalbalitbang.kkp.go.id/index.php/mra/arti cle/view/1007

Ula, M \& Kusnadi, N. 2017. Analsis Budidaya Tambak Bandeng pada Teknologi Tradisional dan Semi Intensif di Kabupaten Kerawang. Forum Agribisnis FA VOL 7 No 1 Maret 2017,

http://journal.ipb.ac.id/index.php/fagb/ article/view/20931

Winarti. L, Herlina. S \& Permadi, R. 2018. Analisis Kelayakan dan Model Pengembangan Usaha Kerupuk Ikan dengan Pendekatan Entrepreneurial Marketing. Jurnal Agribest. Vol. 2 No. 2 http://jurnal.unmuhjember.ac.id/index. php/AGRIBEST/article/view/1622

Winarti. L., 2017. Analisis Resiko Usahatani Ikan Bandeng Di Desa Sungai Undang Kecamatan Seruyan Hilir Kabupaten Seruyan Kalimantan Tengah Vol. 42 No.2 tahun 2017 . https://ojs.uniskabjm.ac.id/index.php/ziraah/article/vi ew/773 